\title{
Determining the Effect of Science Teaching Using Mobile Augmented Reality Application on the Secondary School Students' Attitudes of toward Science and Technology and Academic Achievement
}

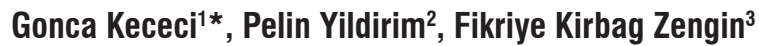 \\ 'Department of Mathematics and Science Education, Faculty of Education, Firat University, Elazig, Turkey, ${ }^{2}$ Institute of Education Sciences, Firat \\ University, Elazig, Turkey, ${ }^{3}$ Department of Mathematics and Science Education, Faculty of Education, Firat University, Elazig, Turkey
}

*Corresponding Author: gkececi@firat.edu.tr

\section{ABSTRACT}

In this research, the effects of science education using mobile augmented reality (MAR) application on students' attitudes toward science, technology, and their academic achievement were determined against two socioeconomic levels. The parallel pattern mixed method was used in the study. The research was carried out with 143 sixth-grade students from two schools with different socioeconomic levels in Turkey. The MAR application was used with the experimental groups. Quantitative data were collected through the "Science and Technology Attitude Scale" and "Systems Achievement Test." According to the ANCOVA results, it was observed that the MAR application used in the processing of the lessons was effective in improving the academic achievement levels of the students but not in attitudes toward science and technology. Results showed that the socioeconomic situation played an active role on the academic achievement of students but did not play an effective role on science and technology attitudes. The results of this research are important in determining the differences between students at different socioeconomic levels experiencing technology-supported systems.

KEY WORDS: academic achievement; attitude; mobile augmented reality; science teaching

\section{INTRODUCTION}

几 he use of technology, which is becoming more and more common in almost every quarter of social lifestyle thanks to the stunning developments in the field of technology, has made it essential for individuals to possess characteristics unique to an information society. Being able to create designs and use technology actively and efficiently, possessing the ability for mobile teaching, and having imagination, creation, and critical thinking skills in the $21^{\text {st }}$ century, also known as "digital era" or "technological era" in numerous platforms, all represent the characteristics of the desired student profile in the $21^{\text {st }}$ century (Education Research and Development Department, 2011). In addition to this, the continuous progress of the developments in the field of technology gaining a great momentum and the consequent increase observed in the number of new generation mobile devices have brought forward the concept of "mobile teaching (m-teaching)" and have put an emphasis on a new education paradigm enabling individuals to have access to information and educational materials independent of when and where. Situated within this education paradigm, mobile teaching is stated to be a teaching model enabling the users to establish connections with other users or mobile devices and individualize the teaching process regardless of when and where by using their personal mobile devices (Ozdamar Keskin, 2011). In recent years, not only the developments in wireless communication and sensor technologies but also the increase in the number of mobile devices developed with the aid of technology has brought along studies aiming to unify this mobile teaching model with education (Ng, 2012). Mobile Augmented Reality (MAR) is notable as it can create a flexible teaching process and environment for students by enabling them to control their own teaching processes and provide an effective teaching environment to diversify and enrich education.

The MAR concept, acknowledged in our day to be an indispensable part of daily life thanks to technologies developed for especially mobile devices, can be defined as providing integration of virtual objects into real-world environments in augmented reality applications through mobile devices (Ifenthaler \& Eseryel, 2013). MAR applications work on the principle of conveying the captured images of an object obtained through various information technologies as a result of processing it to the real world through mobile devices.

It has been observed that the number of studies analyzing the effects of the use of MAR applications on students' attitudes toward science, technology, and their academic achievements 
are limited, and these studies have been carried out in recent years. To illustrate, the objective of one such research carried out by Kücük (2015) was to determine the effects of the use of MAR applications in anatomy education on academic achievement and cognitive loads of medical students, and the students' views on these applications. Following the data analysis obtained through data collection tools, it was concluded that the students in the experimental group in which MAR applications were used were more successful and their cognitive loads less than the students in the control group; and MAG applications reified the subjects, increased the interest levels in the class, and could be beneficial for the students' individual studies by providing a flexible teaching environment. The objective of another research carried out by Sentürk (2018) was to determine the effects of the use of MAG applications in science classes on secondary school students' academic achievements, motivations, and attitudes toward science, technology, and augmented reality (AR) applications. According to the results drawn from that research, it was concluded that the students in the experimental groups in which AR applications were used were more successful and their attitudes toward technology more positive than the students in the control group, and there was a statistically significant difference between the experimental and control groups, and in favor of the experimental groups, in terms of the variables of achievement, motivation, and attitudes toward science and technology. Another research study was carried out in this field by Erbas (2016), the objective of which was to determine the effects of the use of MAR applications in biology classes on students' academic achievements and motivations. According to the results drawn from the research, while it was concluded that AR applications in these classes motivated the students more, no significant difference between the respective academic achievement values of the experimental and control groups was observed.

Research has been carried out on the basis of the facts that the AR technology. AR technology has been shown to be among the promising educational technologies in the recent issues of "Horizon Reports." These reports have been regularly published since 2004. It is argued to occupy a crucial place in education; that there are statements in the body of literature expressing that the studies directed toward the use of AR applications in education are in the infancy stage (Ifenthaler \& Eseryel, 2013; Sentürk, 2018; Sirakaya, 2015; Yilmaz, 2014; Kücük, 2015). There is a need for studies to determine the effects of their use in science education on academic achievements and attitudes toward science.

\section{Problem of Research}

This research was carried out for two main purposes. It aimed to determine the effect of science teaching using MAR application on the secondary school students' attitudes of toward science, technology, and academic achievements. It is also aimed to compare two schools with different socioeconomic levels in terms of variables such as academic achievement and attitude.

\section{Research Focus}

Research has revealed the effects of the use of MAR in science education on academic achievements of secondary school students, a topic that is largely absent in the body of literature; in addition, it will also satisfy the need in the body of literature for studies that should determine the effects of the use of MAR in science education on the attitudes of secondary school students toward science and technology. The results of the research will constitute a resource for researchers and teachers regarding the use of MAR technology which is recognized to be among the promising educational technologies.

Conducted in schools with different socioeconomic levels, the research will also constitute a resource with respect to the effects of the use of MAR technology among two groups; a student group that can access educational technologies with great ease through their own means and another student group that does not have such convenient access.

\section{METHODOLOGY OF RESEARCH}

\section{General Background of Research}

This research builds on a previous study (Yildirim, 2018). For this research to determine the effect of science teaching using MAR application on the secondary school students' academic achievements and attitudes toward science and technology, the mixed method model was preferred because it allowed the use of both quantitative and qualitative data to be consistent, to provide detailed results and to enrich the research findings, and to help the development of the qualitative dimension by quantitative methods. Therefore, mixed method of convergent parallel design was used. Convergent parallel designs are patterns in which the quantitative and qualitative data were collected concurrently and analyzed independently from each other in accordance with the context of the research. This study was carried out in line with the convergent parallel pattern, diaries which reflect the positive/negative emotions and thoughts, observations, and suggestions of the application, which were expressed by the students at the end of each lesson and at the end of each course, were analyzed and analyzed using qualitative analytical methods. Data on students' academic achievements and attitudes were collected and analyzed by quantitative methods. This article describes the part of quantitative data analysis obtained from the "Science and Technology Attitude Scale" and "Systems Achievement Test." SPSS 22 package program was used to analyze the data.

\section{Sample of Research}

The sample of the research was determined based on the parallel mixed method sampling. To determine effects of the socioeconomic levels of the students on various variables, two schools were selected for the purpose sampling within 30 secondary schools which could be classified as high and low socioecenomic level in Elazig, Turkey. In determining the experimental and control groups, year-end averages of branches were taken as the basis. The experimental and control groups of the research were randomly assigned among the 
classes that did not differ between the end-of-year averages. Research group of research was in two state secondary schools' $6^{\text {th }}$ grade total of 143 students, 76 females and 67 males in the 2017-2018 academic year. In the research, schools were coded as the first and second school. The research was carried out with a total of two experiment and two control groups, one experimental and one control group in each school. The experimental and control groups in the first school were experimental-1 and control-1 groups. The experimental and control groups in the second school were experimental-2 and control-2 groups. The research was carried out for a total of eight weeks, including the $6^{\text {th }}$ grade science course curriculum, including the systems unit in our body.

\section{Demographic and Socioeconomic Structures of Students}

Ethics committee approval was obtained from the host university's Social Sciences Research Ethics Committee before the research. Subsequently, an application permit was obtained from the Provincial Directorate of National Education. Later, as the study required voluntary participation, the parents were asked to sign an informed parental consent form, as the students in the study group were under 18 years old.

The student information form was used to determine the demographic characteristics and socioeconomic levels of the students. The distribution of students by schools and gender was as 23 ( 13 females, 10 males) of the experiment- 1 group in the first school, 23 (13 females, 10 males) students in the control-1 group; in the second school, the experiment-2 group consisted of 48 (23 females, 25 males) and the control-2 group consisted of 49 ( 27 females, 22 males) students.

The use of MAR applications requires mobile devices such as tablets and phones. Unfortunately, mobile devices are not equally used at different socioeconomic levels. In this respect, schools with low and high socioeconomic level parents were selected and planned for the research. A comparison of the socioeconomic status of students is given for two different schools. However, no comparison was made between the experimental and control groups because they have similar profiles. Information about the socioeconomic status of the students is shown in Table 1.

When Table 1 is examined, eight students in the first school stated that their mother did not know how to read and write; two of these students stated that their father was illiterate; and 13 of them were primary school graduates. Only two students in the second school stated that their mother was illiterate and 32 students stated that their mother was a university graduate; only one of the students stated that their father was illiterate and 47 of them were university graduates. In addition, there was no student in the first school who stated that their mother had a high school, university, or graduate education.

For 41 students in the first school, their mother was a housewife, while two students were workers; three of these students stated that their father was a worker; and 17 students had retired parents. Sixty-four students in the second school stated that their mother was a housewife and 25 students were civil servants; 49 of the students stated that their father was a civil servant; and 27 of them were workers. In addition, in the first school, "What is your mother's profession?" and "What is your father's profession?" there were no students who flagged the officer option in their questions.

For 20 students in the first school "What is the monthly income of your family?" the question was 0-750 Turkish Lira (TL), 2 students selected the options of $3001 \mathrm{TL}$ and above. In the second school, there were 57 students who selected the option of $3001 \mathrm{TL}$ and above, while there were no students who selected the option of 0-750 TL.

In the first school, 9 students expressed their level of tablet use very well, while the number of students pointing to the same option was 43 in the second school. In addition, eleven students in the first school express their level of internet usage at a very good level, while in the second school, the number of students pointing to the same option was 48 .

"Is there an internet connection in your house?" to the question, 11 of the students in first school selected yes and 34 no in the second school, there were 77 students who selected yes and 18 no.

\section{Instrument and Procedures}

The "Science and Technology Attitude Scale" and "Systems Achievement Test" were used as data collection tools. To determine the attitudes of secondary school students toward science and technology, a five-item Likert-type "Science and Technology Attitude Scale," which was developed by Kececi and Kirbag Zengin (2015), was used. The answers to the items in the scale range from Strongly Agree, Agree, No Idea, Disagree to Strongly Disagree. The Cronbach alpha reliability coefficient of the scale developed by Kececi and Kirbag Zengin (2015) was calculated as .90. To determine the construct validity of the scale developed by the researchers, factor analysis technique was used; the scale was based on three theoretical dimensions: Science and technology, curiosity against science and technology, and attitudes of science and technology in daily life.

To reveal the students' level of understanding of the subject and to measure and evaluate their achievements, the "Systems Achievement Test" consisting of 23 questions, which was developed by authors, was used. Seven questions in the test and movement system, five in the respiratory system, and eleven in the circulatory system. The discriminatory index of 17 items in the test is 0.40 and above, the discriminative index of three items is between 0.30 and 0.39 and the discrimination index of three items is between 0.20 and 0.29 . For the reliability of the test, Cronbach alpha coefficient was calculated as .83, and Spearman-Brown two half test correlation value was calculated as .81 .

In this study, both the "Science and Technology Attitude Scale" and "Systems Achievement Test" were applied to the experimental and control groups as pre-test and post- 


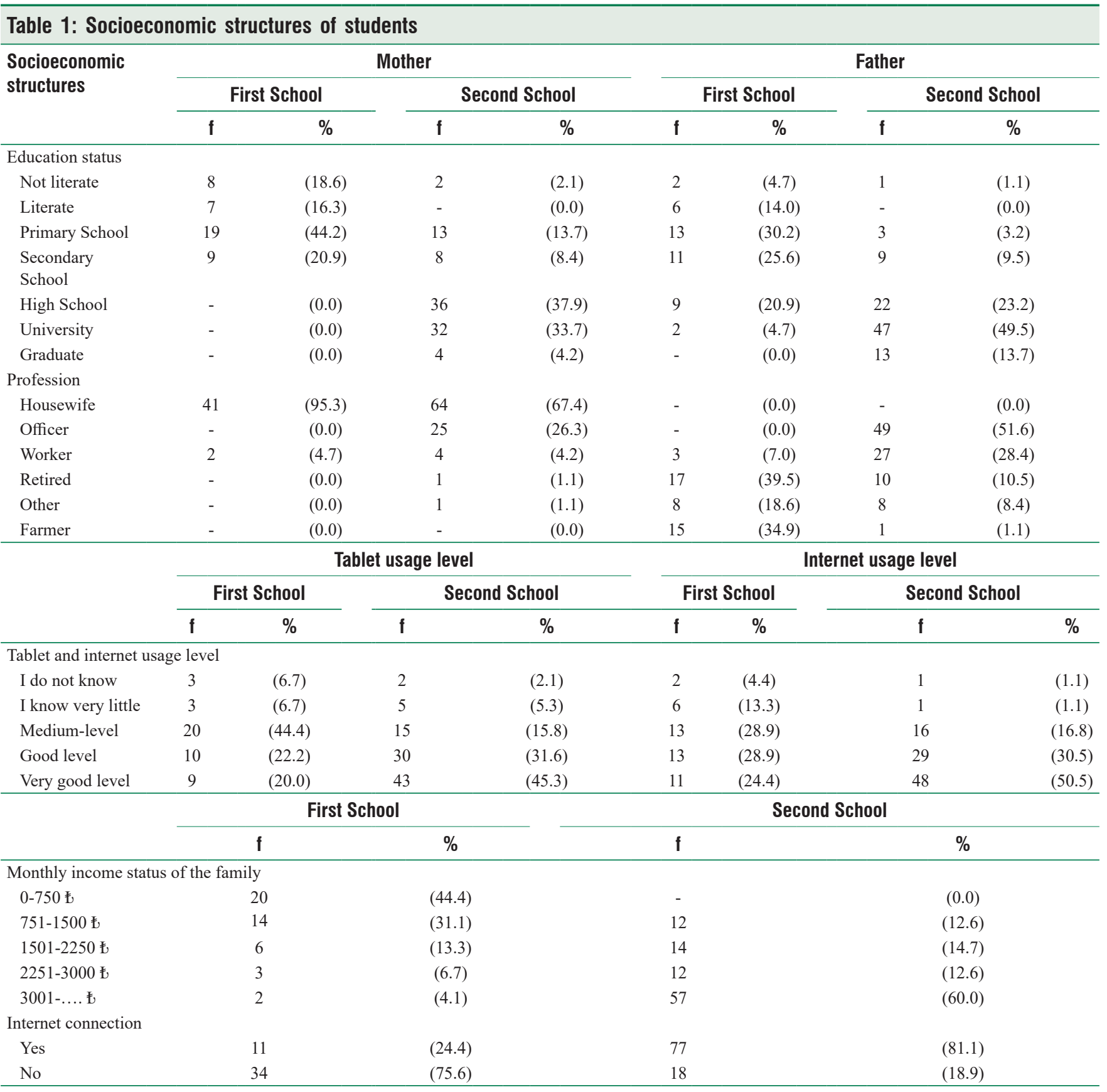

test. The research was carried out for a total of 8 weeks for the systems unit in our body, which is one of the units of the $6^{\text {th }}$-grade science course in the curriculum, was divided into pre-test and post-test applications. During the process, Anatomy 4D application, which is a MAR application, was used in the experimental group, support and movement system, respiratory system, and circulatory system subjects. All the experimental group students used these applications in their school under the guidance of researcher. All the experimental group students used these applications in their school under the guidance of researcher. In control groups, the current textbook was adhered to during the course processing process.
During the process, the researcher provided the application of Anatomy 4D, which he had downloaded to his personal tablet device/smartphone, on the smartboard through a computer program.

In the $1^{\text {st }}$ week of the research, experimental and control groups were determined and the students in the experimental groups were divided into groups to have at least one tablet computer in each group and information about MAR technology was introduced. To allow each student in the experimental groups to use the Anatomy 4D application actively outside the classroom and in the classroom environment during the research period, two worksheets were developed with the use of AR technology. The pre-tests were applied to the experimental and control groups. 
In the $2^{\text {nd }}$ week of the application, Anatomy 4D application was activated on the smartboard and tablet computers and the support and movement system was discussed. Throughout the process, the places of the bones in our body have been shown to be active and the visuals have been enriched with theoretical knowledge and simultaneous teaching has been realized. From time to time, groups were given time to use the application from their tablet computers and their active participation in the process was ensured.

In the $3^{\text {rd }}$ week of the application, questions about bone and joint types were asked to repeat what was done in the previous course using the Anatomy 4D application. The students were asked to show the locations of various bones and joints through the application. After the transition to the muscular system, the muscles in our body have been shown to be active.

In the $4^{\text {th }}$ week, the respiratory system subject was processed through Anatomy 4D application. Throughout the process, the basic organs of the respiratory system were shown in 3D and theoretical information was given about the organs. From time to time, the students were asked to give information about the respiratory system organs and to give feedback.

In the $5^{\text {th }}$ week, on the Anatomy $4 \mathrm{D}$ application, the basic organs of the respiratory system have been shown in 3D and theoretical information is included in the study. From time to time, the students were asked to give information about the respiratory system organs and to give feedback. Subsequently, a short introduction was made to the topic of the circulatory system and the readiness levels of the students were observed.

At the $6^{\text {th }}$ and $7^{\text {th }}$ weeks of the application, the last subject, the circulatory system, was studied. In addition to the "human body" worksheet developed with the AR technology used in the processing of support and movement system and respiratory system issues, the "heart" worksheet was also used to make the teaching about the structure of the heart, which is one of the basic organs of the circulatory system, to make it permanent, and to concretize the abstract concepts that are.

In the last week of the application, the post-tests were applied to the experimental and control groups and the research was completed.

The photographs of the Anatomy 4D application used in the handling of the subjects in the experimental groups throughout the process are given Figure 1:

\section{DATA ANALYSIS}

To address the research questions and developed hypotheses, descriptive analysis was performed on the data of the variables in the experimental and control groups, and the arithmetic averages, standard deviations, skewness and kurtosis values, minimum and maximum values, and Shapiro-Wilk values were calculated. The findings (Tables 2 and 3 ) were used to determine the distribution of variables and their relations with each other.
To test the statistical variables of the variables that are connected with the dependent variable, to test the hypotheses developed, ANCOVA (unidirectional covariance analysis) and unrelated samples t-test were applied to test whether the difference between the two non-related sampling means was significant.

\section{RESULTS OF RESEARCH}

Descriptive statistics numerical data that reflect the frequency and percentage distribution of the variables under the heading of the group are provided. The hypotheses of the research under the heading of inferential statistics through the analysis of the statistical results of the relationship between the dependent and independent variables have been given.

\section{Descriptive Statistics Findings}

The mean distribution of "Science and Technology Attitude Scale" pre-test (STASPRE) and "Science and Technology Attitude Scale" post-test (STASPOST) scores applied to the students of the research were examined. The comparison of the average of the test scores of the research group consisting of secondary school students in the $6^{\text {th }}$ grade, the number of students in the groups, the standard deviations of the groups, the skewness and kurtosis values, and Shapiro-Wilk values with minimum and maximum values are in Table 2.

The mean of the experiment 1 group STASPRE score before the application (mean $=79.43)$ and the control 1 group's STASPRE average (mean $=78.08)$; the mean of the experiment 2 group $($ mean $=84.77)$ and the control 2 group were close to each other $($ mean $=85.65)$, and the attitudes of the students in the groups were close to each other (Table 2).

The difference between the average of the experiment 1 group STASPOST score after the application $($ mean $=82.13)$ and

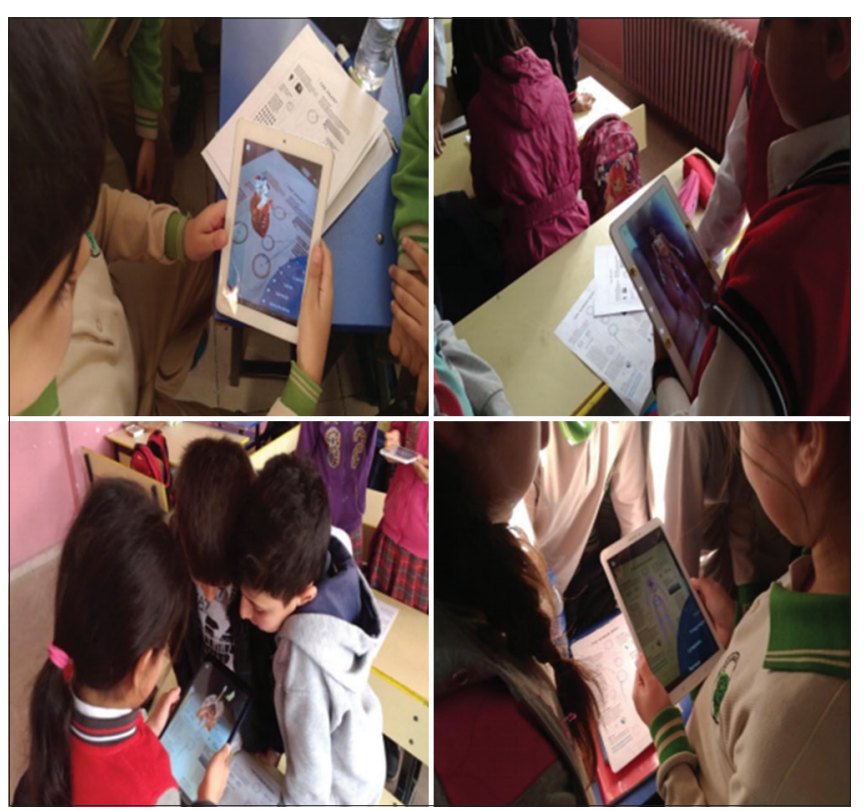

Figure 1: Sample photos of MAR application in experimental groups 
Table 2: Descriptive statistics of pre-test and post-test scores of secondary school students' science and technology attitude scale

\begin{tabular}{|c|c|c|c|c|c|c|c|c|c|c|}
\hline Tests & Groups & $\mathbf{N}$ & Mean & SD & Skewness & Kurtosis & Range & Min & Max & Shapiro-Wilk \\
\hline \multirow[t]{4}{*}{ STASPRE } & Experiment 1 & 23 & 79.43 & 11.74 & -0.443 & -0.045 & 43 & 57 & 100 & 0.940 \\
\hline & Control 1 & 23 & 78.08 & 10.87 & -0.611 & -0.752 & 37 & 55 & 92 & 0.924 \\
\hline & Experiment 2 & 48 & 84.77 & 10.78 & -0.447 & 0.383 & 54 & 56 & 110 & 0.977 \\
\hline & Control 2 & 49 & 85.65 & 7.06 & 0.438 & -0.311 & 32 & 70 & 102 & 0.964 \\
\hline \multirow[t]{4}{*}{ STASPOST } & Experiment 1 & 23 & 82.13 & 7.84 & -0.551 & -0.779 & 25 & 68 & 93 & 0.927 \\
\hline & Control 1 & 23 & 82.04 & 8.87 & 0.196 & 0.078 & 36 & 65 & 101 & 0.969 \\
\hline & Experimental 2 & 48 & 86.89 & 9.88 & -0.407 & 0.607 & 50 & 61 & 111 & 0.980 \\
\hline & Control 2 & 49 & 86.06 & 6.90 & 0.474 & -0.594 & 28 & 74 & 102 & 0.961 \\
\hline
\end{tabular}

\begin{tabular}{|c|c|c|c|c|c|c|c|c|c|c|}
\hline Tests & Groups & $\mathrm{N}$ & Mean & SD & Skewness & Kurtosis & Range & Min & Max & Shapiro-Wilk \\
\hline \multirow[t]{4}{*}{ SATPRE } & Experiment 1 & 23 & 6.08 & 2.08 & -0.290 & -0.957 & 7 & 2 & 9 & 0.944 \\
\hline & Control 1 & 23 & 6.95 & 2.56 & 0.812 & 0.191 & 10 & 2 & 13 & 0.932 \\
\hline & Experiment 2 & 48 & 9.14 & 1.70 & 0.141 & -0.552 & 7 & 6 & 13 & 0.957 \\
\hline & Control 2 & 49 & 9.55 & 2.38 & 0.245 & -0.557 & 10 & 5 & 15 & 0.965 \\
\hline \multirow[t]{4}{*}{ SATPOST } & Experiment 1 & 23 & 16.26 & 3.50 & -0.786 & -0.299 & 13 & 8 & 21 & 0.912 \\
\hline & Control 1 & 23 & 10.95 & 4.58 & 0.139 & -0.830 & 17 & 3 & 20 & 0.968 \\
\hline & Experiment 2 & 48 & 20.12 & 1.63 & -0.363 & -0.200 & 7 & 16 & 23 & 0.955 \\
\hline & Control 2 & 49 & 18.18 & 2.32 & -0.419 & -0.439 & 9 & 13 & 22 & 0.957 \\
\hline
\end{tabular}

the average of the control 1 group $($ mean $=82.04)$ between STASPOST $\left(\right.$ mean $\left._{\text {difference }}=.09\right)$; there was a difference between STASPOST score of the experiment 2 group $($ mean $=86.89)$ and STASPOST average of the control 2 group $($ mean $=86.06)$ between STASPOST $\left(\right.$ mean $_{\text {difference }}=0.83$ ) a difference in value has emerged.

The average distribution of Systems Achievement Test pretest (SATPRE) and Systems Achievement Test post-test (SATPOST) scores applied to the students of the research group was examined. The comparison of the average of the test scores of the research group consisting of junior high school students in the $6^{\text {th }}$ grade, the number of students in the groups, the standard deviations of the groups, the skewness and kurtosis values, and the Shapiro-Wilk values with minimum and maximum values in Table 3.

According to Table 3, the mean of the SATPRE score of the experiment 1 group $($ mean $=6.08)$ was compared with the control 1 group (mean $=6.95)$; It was observed that the average of the SATPRE score of the experiment 2 group (mean $=9.14$ ) and the average of the control 2 group were close to each other $($ mean $=9.55)$.

There was a difference between the mean of SATPOST score of the experiment 1 group $($ mean $=16.26)$ and the mean of SATPOST of the control 1 group $($ mean $=10.95)\left(\right.$ mean $_{\text {difference }}$ $=5.31$ ) after the application; there was a difference between the mean of SATPOST score of the experiment 2 group (mean $=20.12$ ) and the mean of SATPOST of the control 2 group
$($ mean $=18.18)$ between STASPOST $\left(\right.$ mean $\left._{\text {difference }}=1.94\right) \mathrm{a}$ difference in value has emerged.

\section{Results of ANCOVA Analysis}

ANCOVA (unidirectional covariance analysis) was used for the statistical control of the variables connected with the dependent variable to test the developed hypotheses; unrelated samples t-test was applied to test whether the difference between the two non-related sample means was significant. The research group consisted of the students studying in the sixth grade of two different secondary schools in Elazig.

The dependent variables of the research were STASPOST and SATPOST; the independent variables are the group and the subgroup. In the research, the variables of the research were determined to be independent variables, whereas at least one of the dependent variables was used as a common variable. ANCOVA assumptions were tested and assumptions were obtained.

This part of the research; at the end of the experimental process, the pre-test results of the experimental and control groups were taken under control and the results of ANCOVA analysis were performed to check whether the difference between the posttest scores was significant.

Hypothesis 1: There is no significant effect of science teaching using MAR application on the mean of academic achievement post-test scores of students when low socioeconomic level secondary school students' academic achievement pre-test 
scores and pre-test scores of science and technology attitudes are checked.

When the average and corrected mean values of the students in the control and experimental groups in the first school are examined, the average and corrected mean values of the system achievement test post-test scores are examined. Systems Achievement Test post-test mean scores were 13.60 for the students in the experimental and control groups at the first school, and the system test for post-test achievement scores were 13.62 for the students in the experimental and control groups at the first school.

The results of ANCOVA regarding the difference between the post-test mean scores of the groups in the first school are given in Table 4.

When Table 4 is examined, it is seen that Hypothesis 1 has been rejected for the first school. It is seen that the MAR application used in the course had a statistically significant effect on SATPOST scores $(F(1,40)=20.470 ; \rho=.000<.01)$. In addition, the gender variable did not have a significant effect on SATPOST scores $(\rho>.05)$. The obtained eta-square value was interpreted according to Cohen $\mathrm{d}$ index, which is one of the effect size indexes. Cohen (1988) tried to assist in the interpretation of the values obtained by classifying the significance values of effect size values, small values in the range of 0.0 to 0.2 , moderate values in the range of 0.3 to 0.7 , and values in the range of 0.8 to 1.0 , respectively. The results showed that the group variable had a moderate effect on the SATPOST test scores (partial $\mathrm{n}^{2}=.339$ ) and $33.9 \%$ of the change in the dependent variable was due to the method applied.

Hypothesis 2: There is no significant effect of science teaching using MAR application on the mean of academic achievement post-test scores of high socioeconomic level secondary school students when students' academic achievement pre-test scores and pre-test scores of science and technology attitudes are checked.

When the average and corrected mean values of the students in the control and experiment groups in the second school are examined, the average and corrected mean values for

\begin{tabular}{|c|c|c|c|c|c|c|c|}
\hline Source & $\begin{array}{l}\text { Sum of } \\
\text { squares }\end{array}$ & df & $\begin{array}{l}\text { Mean } \\
\text { square }\end{array}$ & $F$ & Sig. & $\eta 2$ & $\begin{array}{l}\text { Observed } \\
\text { difficulty }\end{array}$ \\
\hline $\begin{array}{l}\text { Corrected } \\
\text { model }\end{array}$ & 447.170 & 5 & 89.434 & 5.867 & 0.000 & 0.423 & 0.987 \\
\hline Intercept & 2.068 & 1 & 2.068 & 0.136 & 0.715 & 0.003 & 0.065 \\
\hline SATPRE & 5.353 & 1 & 5.353 & 0.351 & 0.557 & 0.009 & 0.089 \\
\hline STASPRE & 99.179 & 1 & 99.179 & 6.506 & 0.015 & 0.140 & 0.702 \\
\hline Group & 312.056 & 1 & 312.056 & 20.470 & 0.000 & 0.339 & 0.993 \\
\hline Gender & 0.830 & 1 & 0.830 & 0.054 & 0.817 & 0.001 & 0.056 \\
\hline Error & 609.786 & 40 & 15.245 & & & & \\
\hline Total & 9576.000 & 46 & & & & & \\
\hline $\begin{array}{l}\text { Corrected } \\
\text { total }\end{array}$ & 1056.957 & 45 & & & & & \\
\hline
\end{tabular}

the System Achievement Test post-test scores are examined. Systems Achievement Test post-test mean scores were 19.14 for the students in the experimental and control groups at the second school, and the post-test mean scores of the Systems Achievement Test were 19.11 for the students in the experimental and control groups at the second school.

The results of ANCOVA regarding the difference between the post-test mean scores of the second school groups are given in Table 5.

Hypothesis 2 has been rejected for the second school (Table 5). It is seen that the MAR application used in the course had a statistically significant effect on SATPOST scores $(\mathrm{F}(1,91)=$ $26,758 ; \rho=0.000<0.01)$. In addition, the gender variable did not have a significant effect on SATPOST scores $(\rho>0.05)$. The results showed that the group variable had a moderate effect on the SATPOST test scores (partial $\mathrm{n}^{2}=0.227$ ) and $22.7 \%$ of the change in the dependent variable was due to the method applied.

Hypothesis 3. There is no significant effect of science teaching using MAR application on the mean of science and technology attitudes post-test scores of low socioeconomic level secondary school students when students' academic achievement pre-test scores and science and technology attitudes pre-test scores are checked.

When the average and corrected mean values of the students in the control and experimental groups in the first school are examined, the average and corrected mean values of the Science and Technology Attitude Scale post-test scores; posttest mean scores of Science and Technology Attitude Scale were 82.08 for the students in the experimental and control groups at the first school, and the post-test mean scores for the Science and Technology Attitude Scale were 82.01 for the students in the experimental and control groups at the first school.

The results of ANCOVA regarding the difference between the post-test mean scores of the first school groups were given in Table 6.

\begin{tabular}{lllllllll}
\hline $\begin{array}{l}\text { Table 5: ANCOVA results of SATPOST points of } \\
\text { experimental and control groups in second school }\end{array}$ \\
\begin{tabular}{lllllllll} 
Source & $\begin{array}{c}\text { Sum of } \\
\text { squares }\end{array}$ & df & $\begin{array}{c}\text { Mean } \\
\text { square }\end{array}$ & F & Sig. & n2 & $\begin{array}{c}\text { Observed } \\
\text { difficulty }\end{array}$ \\
\hline $\begin{array}{l}\text { Corrected } \\
\text { model }\end{array}$ & 141.079 & 5 & 28.216 & 7.667 & 0.000 & 0.296 & 0.999 \\
Intercept & 392.176 & 1 & 392.176 & 106.563 & 0.000 & 0.539 & 1.000 \\
SATPRE & 16.077 & 1 & 16.077 & 4.369 & 0.039 & 0.046 & 0.543 \\
STASPRE & 12.400 & 1 & 12.400 & 3.369 & 0.070 & 0.036 & 0.443 \\
Group & 98.474 & 1 & 98.474 & 26.758 & 0.000 & 0.227 & 0.999 \\
Gender & 1.200 & 1 & 1.200 & 0.326 & 0.569 & 0.004 & 0.087 \\
Error & 334.900 & 91 & 3.680 & & & & \\
Total & 36027.000 & 97 & & & & & \\
Corrected & 475.979 & 96 & & & & & \\
total & & & & & & & \\
\hline
\end{tabular}
\end{tabular}


When Table 6 is examined, it is seen that Hypothesis 3 is accepted for the first school. It is seen that the MAR application used in the course did not have a statistically significant effect on STASPOST scores $(\mathrm{F}(1,40)=.060 ; \rho=0.808>$ $0.01)$. In addition, there was no significant effect of gender on STASPOST scores $(\rho>.05)$. The result obtained was that the group variable had a small effect on the STASPOST test scores (partial $\mathrm{n}^{2}=.002$ ).

Hypothesis 4: There is no significant effect of science teaching using MAR application on the mean of science and technology attitudes post-test scores of high socioeconomic level secondary school students when students' academic achievement pre-test scores and science and technology attitudes pre-test scores are checked.

When the mean and corrected mean values of the students in the control and experimental groups in the second school are examined, the mean and corrected mean values of the Science and Technology Attitude Scale post-test scores; the last test mean scores of the Science and Technology Attitude Scale were 86.47 for the students in the experimental and control groups at the second school while the post-test mean scores of the Science and Technology Attitude Scale were corrected 86.53 for the students in the experimental and control groups at the second school.

The results of ANCOVA regarding the difference between the post-test mean scores of the second school groups are given in Table 7.

As evidenced by Table 7, Hypothesis 4 is accepted for the second school. It is seen that the MAR application used in the course did not have a statistically significant effect on STASPOST scores $(F(1,91)=.651 ; \rho=.422>.01)$. In addition, there was no significant effect of gender on STASPOST scores $(\rho>.05)$. The result obtained was that the group variable had a small effect on the STASPOST test scores (partial $\mathrm{n}^{2}=.007$ ).

Hypothesis 5: There is no statistically significant difference between the achievement test pre-test and post-test mean scores between two schools with different socioeconomic levels.

\begin{tabular}{|c|c|c|c|c|c|c|c|}
\hline Source & $\begin{array}{l}\text { Sum of } \\
\text { Squares }\end{array}$ & df & $\begin{array}{l}\text { Mean } \\
\text { Square }\end{array}$ & $F$ & Sig. & $n 2$ & $\begin{array}{l}\text { Observed } \\
\text { Difficulty }\end{array}$ \\
\hline $\begin{array}{l}\text { Corrected } \\
\text { Model }\end{array}$ & 302.446 & 5 & 28.216 & 0.869 & 0.510 & 0.098 & 0.278 \\
\hline Intercept & 4023.901 & 1 & 392.176 & 57.831 & 0.000 & 0.591 & 1.000 \\
\hline SATPRE & 6.614 & 1 & 16.077 & 0.095 & 0.759 & 0.002 & 0.060 \\
\hline STASPRE & 87.151 & 1 & 12.400 & 1.253 & 0.270 & 0.030 & 0.194 \\
\hline Group & 4.186 & 1 & 98.474 & 0.060 & 0.808 & 0.002 & 0.057 \\
\hline Gender & 13.592 & 1 & 1.200 & 0.195 & 0.661 & 0.005 & 0.072 \\
\hline Error & 2783.206 & 40 & 3.680 & & & & \\
\hline Total & 313046.000 & 46 & & & & & \\
\hline $\begin{array}{l}\text { Corrected } \\
\text { Total }\end{array}$ & 3085.652 & 45 & & & & & \\
\hline
\end{tabular}

The t-test results of the unrelated samples regarding the significance of the difference between the pre-test and post-test point averages of experiment 1 and experiment 2 groups are given in Table 8 .

Table 8 indicates that Hypothesis 5 is rejected. The mean of pretest scores of the groups for the SATPRE scores was 6.08 for the experiment 1 group and 9.14 for the experiment 2 group. When the measurement scores were compared, it was observed that there was a statistically significant difference between the pre-test scores of the students in the experiment 2 groups in the school having high socioeconomic level and in the experiment 1 school $(\mathrm{t}(69)=6.58 ; \rho=.000<.01)$. In addition, the posttest mean scores of the groups for the SATPOST scores were $=$ 16.26 for the experiment 1 group and 20.12 for the experiment 2 group. When the measurement scores are compared, it is observed that there is a statistically significant difference between the students in the experiment 2 groups in the school with low socioeconomic level and the students in the experiment 2 groups $(\mathrm{t}(26.67)=5.03 ; \rho=0.000<0.01)$.

Hypothesis 6: There is no statistically significant difference between the pre-test and post-test mean scores of science and technology attitudes between two schools with different socioeconomic levels.

The t-test results of the unrelated samples of the difference between the mean and the pre-test and post-test mean scores of experiment 1 and experiment 2 groups were given in Table 9 .

According to Table 9, it is seen that Hypothesis 6 is accepted. For the experiment 1 group, the mean pre-test scores of the groups were 79.43 for the experiment 1 group and 84.77 for

\begin{tabular}{|c|c|c|c|c|c|c|c|}
\hline Source & $\begin{array}{l}\text { Sum of } \\
\text { squares }\end{array}$ & df & $\begin{array}{l}\text { Mean } \\
\text { square }\end{array}$ & $F$ & Sig. & n2 & $\begin{array}{l}\text { Observed } \\
\text { difficulty }\end{array}$ \\
\hline $\begin{array}{l}\text { Corrected } \\
\text { model }\end{array}$ & 2228.917 & 5 & 445.783 & 8.695 & 0.000 & 0.323 & 1.000 \\
\hline Intercept & 1657.592 & 1 & 1657.592 & 32.333 & 0.000 & 0.262 & 1.000 \\
\hline SATPRE & 8.102 & 1 & 8.102 & 0.158 & 0.692 & 0.002 & 0.068 \\
\hline STASPRE & 2107.839 & 1 & 2107.839 & 41.115 & 0.000 & 0.311 & 1.000 \\
\hline Group & 33.354 & 1 & 33.354 & 0.651 & 0.422 & 0.007 & 0.126 \\
\hline Gender & 1.947 & 1 & 1.947 & 0.038 & 0.846 & 0.000 & 0.054 \\
\hline Error & 4665.268 & 91 & 51.267 & & & & \\
\hline Total & 732240.000 & 97 & & & & & \\
\hline $\begin{array}{l}\text { Corrected } \\
\text { total }\end{array}$ & 6894.186 & 96 & & & & & \\
\hline
\end{tabular}

Table 8: t-test results of SATPRE and SATPOST points of experiment 1 and experiment 2 groups

\begin{tabular}{llllcrrr}
\hline Variables & Groups & N & Mean & SD & df & t & Sig. \\
\hline SATPRE & Experiment 1 & 23 & 6.08 & 2.08 & 69 & 6.58 & 0.000 \\
& Experiment 2 & 48 & 9.14 & 1.70 & & & \\
SATPOST & Experiment 1 & 23 & 16.26 & 3.50 & 26.67 & 5.03 & 0.000 \\
& Experiment 2 & 48 & 20.12 & 1.63 & & &
\end{tabular}




\begin{tabular}{|c|c|c|c|c|c|c|c|}
\hline Variables & Groups & $\mathbf{N}$ & Mean & SD & df & $t$ & Sig. \\
\hline \multirow[t]{2}{*}{ STASPRE } & Experiment 1 & 23 & 79.43 & 11.74 & 69 & 1.89 & 0.062 \\
\hline & Experiment 2 & 48 & 84.77 & 10.78 & & & \\
\hline \multirow[t]{2}{*}{ STASPOST } & Experiment 1 & 23 & 82.13 & 7.84 & 69 & 2.02 & 0.047 \\
\hline & Experiment 2 & 48 & 86.89 & 9.88 & & & \\
\hline
\end{tabular}

the experiment 2 group. When the measurement scores were compared, it was observed that there was no statistically significant difference between the pre-test scores of the students in the experiment 2 groups in the school with high socioeconomic level and the experiment 1 in the school with high socioeconomic level (t $(69)=1.89 ; \rho=.062>.01)$. In addition, the post-test mean scores of the groups for the STASPOST scores were 82.13 for the experiment 1 group and 86.89 for the experiment 2 group. When the measurement scores were compared, it was seen that there was no statistically significant difference between the students in the experiment 2 groups in the school having high socioeconomic level and the students in the experiment 2 groups at the lower socioeconomic level $(\mathrm{t}(69)=2.02 ; \rho=0.047>0.01)$.

\section{DISCUSSION}

Through this research, the effects of science education carried out through the use of the MAR application on secondary school students' academic achievements and attitudes toward science and technology were determined, and two schools different in socioeconomic terms were compared within the scope of variables such as academic achievement and attitude.

It was concluded that even though the mean values of the students in the experimental group-1 in which MAR applications were used in classes regarding their attitudes toward science and technology were higher than the mean values of the students in the control group-1 in which standard course books were still applied in classes regarding their attitudes toward science and technology, there was no statistically significant difference between the attitudes of the students in the experimental group- 1 toward science and technology and the attitudes of the students in the control group-1 toward science and technology. Likewise, it was acknowledged that while the mean values of the students in the experimental group- 2 in which MAR applications were used in classes regarding their attitudes toward science and technology were higher than the mean values of the students in the control group-2 in which standard course books were still applied in classes regarding their attitudes toward science and technology, there was no statistically significant difference between the attitudes of the students in the experimental group- 2 toward science and technology and the attitudes of the students in the control group-2 toward science and technology. The obtained results may indicate that the MAR application used in classes did not play a determinant role in the development of the students' attitudes toward science and technology. In addition to this, the pre-test and post-test mean values of the students in the experimental group-1 and the control group-1 in Science and Technology Attitude Scale were concluded to be lower than the pre-test and post-test mean values of the students in the experimental group- 2 and the control group- 2 in Science and Technology Attitude Scale. The lower socioeconomic levels, inclination capacities toward technology, and technological device possession and internet access levels of the students in the experimental group-1 and the control group-1 compared to those in the experimental group-2 and the control group-2 may be included within the reasons for the aforementioned conclusions. Upon the examination of the related body of literature, it can be seen that the number of studies analyzing the effects of the use of AR or MAR applications in classes on students' attitudes toward science and technology is highly limited. In his research, Sahin (2017) investigated the effects of science education performed with augmented reality technology on students' attitudes toward the class and concluded that the use of AR technology in the class had a positive effect on the students' attitudes. In his research, Yildirim (2016) investigated the effects of science education performed with AR technology on students' attitudes toward the class and concluded that the use of AR technology in the class the students' motivations for the class.

The conclusions of the studies carried out by Sahin (2017) and Yildirim (2016) regarding the students' attitudes toward science and technology coincide with the conclusions of this research regarding the same topic. The frequency of the use of new generation technologies in educational environments and the extreme difficulty to change the attitude variable in cognitive variables in a six-week time period excluding the 2 -week pre-test and post-test practices may be included among the reasons for the differences in the students' attitudes toward science and technology.

In this day and age when a need for raising individuals who think, question, search, investigate, use technology actively and effectively, put theoretical information into practice, and possess the capacity for mobile teaching is emphasized along with the necessities of the current times and the developments in the field of technology; it is supposed that individuals with such characteristics can indeed be raised and their attitudes toward classes will be represented with high-level values through increasing the frequency of the use of new generation technologies and information technology tools in educational environments.

It was concluded that the academic achievement values of the students in the experimental group-1 and the experimental group-2 in which MAR applications were used in classes were significantly higher in statistical terms than those of the students in the control group-1 and the control group-2 in which course books were still adhered, respectively. In addition, the obtained data from ANCOVA statistics performed to ascertain the effects of the use of the MAR applications in classes on students' academic achievements indicate that teaching with 
MAR applications has a significant impact on academic achievement levels. These obtained results may assert that the use of MAR applications in classes is highly effective in the development of student' academic achievement levels.

Higher post-test values of the students in the experimental groups regarding their academic achievements compared to the students in the control groups may be related to performing a technology-based education by integrating technological devices into educational environments in the experimental groups. Indeed, through the integration of new technologies into educational environments, students are intrigued; they are enabled to play an active role in the teaching process; and they are provided with the chance to understand the subjects more easily by increasing their interests and drives (Kreijns et al., 2013; Shen et al., 2013).

While the number of studies analyzing the effects of the use of AR and MAR applications on students' academic achievement levels is limited, the conclusions drawn from this research regarding the students' achievement levels in classes coincide with the conclusions drawn from other studies performed with the same objectives (Kücük, 2015; Sirakaya, 2015; Yildirim, 2016; Demirel, 2017; Sahin, 2017). Wicaksono and Madlazim (2017) reported that Virtual Scientific Teaching Model application gives a consistent impact on improving each student's scientific creativity indicator. This situation shows that the effects of virtual reality and augmented reality applications should be investigated in many ways.

Regarding the two schools with different socioeconomic levels, it was concluded that the SAT pre-test means value of the experimental group-1 in the school with lower socioeconomic level was lower than the SAT pre-test mean value of the experimental group-2 in the school with higher socioeconomic level; and that there was a statistically significant difference between the SAT pre-test values of the experimental group- 1 in the school with lower socioeconomic level and the experimental group-2 with higher socioeconomic level, in favor of the latter. Likewise, it was concluded that the SAT post-test mean value of the experimental group-1 in the school with lower socioeconomic level was lower than the SAT post-test mean value of the experimental group-2 in the school with higher socioeconomic level; and that there was a statistically significant difference between the SAT post-test values of the experimental group-1 in the school with lower socioeconomic level and the experimental group-2 with higher socioeconomic level, in favor of the latter. In this context, socioeconomic factors can be recognized to play an active role in the development of students' academic achievement levels.

Within the scope of research, the studies carried out by Tavsancil and Yalcin (2015), Kilic and Askin (2013), Akyüz (2014), Bos and Kuiper (1999) concluded that the academic achievement levels of students with high socioeconomic levels are relatively higher. The conclusions drawn from these studies support the conclusions of this research regarding the effects of socioeconomic factors on students' academic achievements.
Borich (2014) states for researchers that the socioeconomic conditions of students reflect the educational background and the level of income of their parents directly, and the conditions of the school they research at indirectly. Sirin (2005) also makes statements similar to the ideas of Borich (2014) by claiming that among high-status indicators are various factors such as parents' level of income, educational background, and profession. The access of students with higher socioeconomic levels to various platforms of information at earlier ages than those with lower socioeconomic levels; the difference in the levels of access to books, various educational resources, information technologies, internet access opportunities, and social networks in favor of students with higher socioeconomic levels; and more fund appropriation for the education of students coming from families with high socioeconomic levels compared to those coming from families with lower socioeconomic levels (Education Reform Initiative, 2014) are all indicators of the difference in the students' pre-test values of their academic achievement.

Regarding the two schools with different socioeconomic levels, the STAS (Science and Technology Attitude Scale) pre-test mean value of the experimental group-1 in the school with lower socioeconomic levels was concluded to be lower than the STAS pre-test mean value of the experimental group- 2 in the school with higher socioeconomic levels, and that there was no statistically significant differences between the STAS pre-test mean values of these two schools with different socioeconomic levels. In addition, the STAS (Science and Technology Attitude Scale) post-test mean value of the experimental group-1 in the school with lower socioeconomic levels was concluded to be lower than the STAS post-test mean value of the experimental group-2 in the school with higher socioeconomic levels, and that there was no statistically significant differences between the STAS post-test mean values of these two schools with different socioeconomic levels. In this regard, it can be said that socioeconomic factors do not play a significant role in students' attitudes toward science and technology.

In their research, Henno and Reiska (2013) declared that the socioeconomic background of the school has no direct impact on students' general interest in teaching science, instrumental motivation, future-oriented science motivation, or self-concept in science. In his research, Cibisoglu (2016) analyzed the effects of socioeconomic factors on students' attitudes toward foreign language education and concluded that there was no statistically significant difference between the values of students' aforementioned attitudes. This conclusion drawn from the research of the researchers supports the conclusion of this research the effects of socioeconomic factors on students' attitudes toward science and technology. The extreme difficulty to change the attitude variable in cognitive variables in a 6-week time period excluding the 2-week pre-test and post-test practices may have been effective in the fact that there was no statistically significant difference between the STAS post-test mean values of two schools with different socioeconomic levels. 


\section{CONCLUSIONS}

When the literature on the use of MAR applications in education is examined, it is seen that the number of studies performed is limited, and the sample group is composed mostly of secondary or university students and it has been performed in recent years. On the other hand, when the literature about the use of AR applications in education, it is seen that the number of studies carried out in this area is higher than the number of studies aimed at using MAR applications in education. Nowadays, technology-based education is inevitable, and researchers can contribute to the literature by including new technologies, including AR and MAR applications, and enable technology-based education to be realized by integrating technological tools into educational environments.

It was concluded that the MAR application used in the course of the course provided a positive increase in the academic achievement of the students in the experimental groups but not a significant increase in their attitudes toward science and technology. This situation is thought to be related to students' being introduced to MAR application and to being used to traditional teaching methods. Mobile applications are taking place in our lives with every passing day and even the majority of our time is spent with these applications. Therefore, researchers are recommended to make more extensive studies on the use of mobile applications in education. To increase the awareness of individuals about the targeted features in the $21^{\text {st }}$ century, it is recommended that researchers should examine the effectiveness of MAR technology on various variables such as academic achievement, attitude, imagination, problem-solving, creative and critical thinking skills, and to design their studies in this direction.

\section{ACKNOWLEDGMENTS}

This research builds upon a part of the master dissertation entitled "The Impact of Science Teaching Made with Mobile Augmented Reality Technology on Science and Technology Attitudes and Academic Achievement of Secondary School Students." We would like to thank Firat University Scientific Research Projects Unit for funding this master thesis.

\section{REFERENCES}

Akyüz, G. (2014). The effects of student and school factors on mathematics achievement in TIMSS 2011. Education and Science, 39(172), 150-162.

Borich, G.D. (2014). Effective Teaching Methods. Nobel Publisher.

Bos, K., \& Kuiper, W. (1999). Modelling TIMSS data in a european comparative perspective: Exploring influencing factors on achievement in mathematics in grade 8. Educational Research and Evaluation, 5(2), 57-179.

Cibisoglu, M.A. (2016). The Effect of Students' Social Origin to Foreign Language Achievement and Attitude for Language Learning. Master's thesis, Ankara University, Ankara, Turkey.

Cohen, J. (1988). Statistical Power Analysis for the Behavioral Sciences. ( $2^{\text {nd }}$ ed. $)$. Lawrence Earlbaum Associates.

Demirel, T. (2017). The Effect of Augmented Reality Activities Supported by Argumentation Approach on Academic Achievement, Critical Thinking Skills, Motivation Towards Science and Technology Course and Argumentation Skills. (Doctoral Thesis). Adana: Cukurova University.
Education Reform Initiative. (2014). Equality and Academic Achievement Research Report and Analysis in Turkish Education System. Istanbul, Turkey: Sabanci University. Available from: http:// www.egitimreformugirisimi.org/wp-content/uploads/2017/03/ ERG T\%C3\%BCrkiye-E\%C4\%9Fitim-Sisteminde-E $\% \mathrm{C} 5 \% 9$ Fitlikve-Akademik-Ba $\%$ C5\%9Far-Ara $\%$ C $5 \% 9 F t \% C 4 \% B 1$ rma-Raporu-veAnaliz.pdf.

Education Research and Development Department. (2011). MEB 21 st Century Student Profile. New Delhi: Ministry of Education. Available from: http://www.meb.gov.tr/earged/earged/21.\%20yy_og_pro.pdf.

Erbas, Ç. (2016). The Effects of Mobile Augmented Reality Applications on Students' Academic Achievement and Motivation. Master's thesis, Suleyman Demirel University, Isparta, Turkey.

Henno, I., \& Reiska, P. (2013). Impact of the sociocultural context on student science performance and attitudes: The case of Estonia. Journal of Baltic Science Education, 12(4), 465-481.

Ifenthaler, D., \& Eseryel, D. (2013). Facilitating complex learning by mobile augmented reality learning environments. In R. Huang, J.M. Spector, H. Kinshuk (Eds.), Reshaping Learning: Frontiers of Learning Technologies in a Global Context (pp. 415-438). Springer.

Kececi, G., \& Kirbag Zengin, F. (2015). Science and technology attitude scale for secondary school students: Validity and reliability study. Turkish Journal of Educational Studies, 2(2), 143-168.

Kilic, S., \& Askin, Ö.E. (2013). Parental influence on students' mathematics achievement: The comparative study of Turkey and best performer countries in TIMSS. Procedia - Social and Behavioral Sciences, 106, 2000-2007.

Kreijns, K., Acker, F.V., Vermeulen, M., \& Buuren, H.V. (2013). What stimulates teachers to integrate ICT in their pedagogical practices? The use of digital learning materials in education. Computers in Human Behavior, 29, 217-225.

Kücük, S. (2015). Effects of Learning Anatomy via Mobile Augmented Reality on Medical Students' Academic Achievement, Cognitive Load, and Views Toward Implementation. Doctoral thesis, Ataturk University, Erzurum, Turkey.

Ng, J.K.Y. (2012). Ubiquitous healthcare: Healthcare systems and applications enabled by mobile and wireless. Journal of Convergence, 3(2), 15-20.

Özdamar Keskin, N. (2011). Development and Testing of a M-learning System for the Professional Development of Academics through Designbased Action Research. Master's thesis, Anadolu University, Eskisehir, Turkey.

Shen, C.X., Liu, R.D., \& Wang, D. (2013). Why are children attracted to the internet? The role of need satisfaction perceived online and perceived in daily real life. Computers in Human Behavior, 29(1), 185-192.

Sirakaya, M. (2015). The Effect of Augmented Reality Use on Achievement, Misconception and Course Engagement. Doctoral thesis, Gazi Universtiy, Ankara, Turkey.

Sirin, S.R. (2005). Socioeconomic status and academic achievement: A meta-analytic review of research. Review of Educational Research, 75(3), 417-453.

Sahin, D. (2017). Effects of Learning Anatomy Via Mobile Augmented Reality on Medical Students'Academic Achievement, Cognitive Load, and Views Toward Implementation. (Master Thesis). Erzurum: Ataturk University.

Sentürk, M. (2018). The Investigation with Solomon Four-group Design on the Effect of Using Mobile Augmented Reality (AR) Applications in the Unit Titled Solar System and Beyond in the Seventh-grade on the Students' Academic Success, Motivation, Science and Technology Attitude. Master's thesis, Kocaeli University, Kocaeli, Turkey.

Tavsancil, E., \& Yalcin, S. (2015). A determination of Turkish student's achievement using hierarchical linear models in Trends in International Mathematics-Science Study (TIMSS) 2011. The Anthropologist, 22(2), 390-396.

Wicaksono, I., \& Madlazim, W. (2017). The effectiveness of virtual science teaching model (VS-TM) to improve student's scientific creativity and concept mastery on senior high school physics subject. Journal of Baltic Science Education, 16(4), 549-561.

Yildirim, P. (2018). The Impact of Science Teaching Made with Mobile 
Augmented Reality Technology on Science and Technology Attitudes and Academic Achievement of Secondary School Students. Master's thesis, Firat University, Elazig, Turkey.

Yildirim, S. (2016). The Impact of Augmented Reality to Student's Success, Motivation, and their Perception and Behavior Related to Problem
Solving Abilities in Science Classes. Master's thesis, Ankara University, Ankara, Turkey.

Yilmaz, R.M. (2014). Effects of Three Dimensional Storytelling Developed with Augmented Reality Technology on Narrative Skill and Creativity. Doctoral thesis, Ataturk University, Erzurum, Turkey. 